\title{
Efficacy and safety of paliperidone palmitate 3-month formulation in Latin American patients with schizophrenia: A subgroup analysis of data from two large phase 3 randomized, double-blind studies
}

\author{
Adam J. Savitz, ${ }^{1}$ iD Haiyan Xu, ${ }^{1}$ Srihari Gopal, ${ }^{1}$ Isaac Nuamah, ${ }^{1}$ Maju Mathews, ${ }^{2}$ Bernardo Soares ${ }^{3}$ \\ ${ }^{1}$ Janssen Research \& Development, LLC, Pennington, NJ, USA. ${ }^{2}$ Janssen Research \& Development, LLC, Titusville, NJ, USA. ${ }^{3}$ Janssen-Cilag \\ UK, Buckinghamshire, UK.
}

\begin{abstract}
Objective: To analyze the efficacy and safety of paliperidone palmitate 3-monthly (PP3M) in Latin American patients with schizophrenia vs. rest-of-world (ROW).

Methods: We analyzed data from two multinational, double-blind (DB), randomized, controlled phase 3 studies including patients with schizophrenia (DSM-IV-TR) previously stabilized on PP1M/PP3M (open-label [OL] phase). Patients were randomized to PP3M or PP1M (noninferiority study A) and PP3M or placebo (study B) in DB phase. The subgroup analysis included Latin American (Argentina, Brazil, Colombia, Mexico) patients. Primary efficacy endpoints were relapse-free rates (study $A$ ) and time-to-relapse (study B).

Results: In study A, 63/71 (88.7\%) and in study B 38/43 (88.4\%) Latin American patients completed the DB phase. In study A, relapse-free percentage was similar in Latin America (PP3M: 97\%, PP1M: 100\%) and ROW (PP3M: 91\%, PP1M: 89\%). In study B, median time-to-relapse was not estimable in the Latin American subgroup for either placebo or PP3M groups, nor for the ROW PP3M group; the median time-to-relapse in the ROW placebo group was 395 days. Caregiver burden improved in patients switching from oral antipsychotics (OL baseline) to PP3M/PP1M in DB phase (Involvement Evaluation Questionnaire score mean \pm SD change, -9.4 $\pm 15.16 ; p<0.001)$. Treatment emergent adverse events with PP3M during DB phase were similar in Latin America (study A: 24/34 [70.6\%]; study B: $15 / 21$ [71.4\%]) and ROW (study A: 318/470 [67.7\%]; study B: 84/139 [60.4\%]) subgroups. Conclusion: PP3M was efficacious and showed no new safety concerns in patients with schizophrenia from Latin America, corroborating ROW findings.

Clinical trial registration: NCT01515423, NCT01529515
\end{abstract}

Keywords: Paliperidone palmitate once-monthly; paliperidone palmitate three-monthly; relapse prevention; schizophrenia

\section{Introduction}

Relapse in schizophrenia can lead to progressive psychosocial, occupational, and neurological deterioration, with loss of productivity and increased caregiver burden and healthcare utilization. ${ }^{1,2}$ Poor adherence to medication and longer duration of illness (particularly $>10$ years) may increase the likelihood of relapse, and therefore uninterrupted, early intervention is desirable. ${ }^{3}$ Long-acting injectable (LAI) antipsychotics have been shown to improve medication adherence and lower the incidence of treatment discontinuation, relapse, and rehospitalization by offering advantages of consistent bioavailability, predictable plasma concentrations, lower frequency of dosing,

Correspondence: Adam J. Savitz, Janssen Research \& Development, LLC, 1800 American Boulevard, Pennington, NJ, USA.

E-mail: asavitz@its.jnj.com

Submitted May 09 2018, accepted Nov 26 2018, Epub Apr 152019. and feasibility of tracking adherence and treatment response via regular appointments. ${ }^{4-8}$

Clinically meaningful improvements in acute symptom exacerbations, ${ }^{9-11}$ relapse prevention, ${ }^{12}$ and long-term maintenance treatment $^{13-15}$ have been observed with paliperidone palmitate once-monthly (PP1M) LAI in over 3,000 patients with schizophrenia. The newer paliperidone palmitate 3-month formulation (PP3M) LAl offers a 3-month dosing interval, with only four injections per year, which improves the prospects for adherence and lowers the risk of symptom exacerbations owing to maintained therapeutic plasma concentrations. ${ }^{16,17}$ In two large prospective phase 3 studies, PP3M achieved steady-state exposure and demonstrated efficacy in reducing relapse

How to cite this article: Savitz AJ, Xu H, Gopal S, Nuamah I, Mathews M, Soares B. Efficacy and safety of paliperidone palmitate 3-month formulation in Latin American patients with schizophrenia: A subgroup analysis of data from two large phase 3 randomized, double-blind studies. Braz J Psychiatry. 2019;41:499-510. http://dx. doi.org/10.1590/1516-4446-2018-0153 
rates in patients with schizophrenia previously stabilized with PP1M. ${ }^{18,19}$

Because large international multicenter studies involve different patient populations, and regional effects may interfere with data homogeneity, regional subgroup analyses are desirable. ${ }^{20}$ Global data on PP3M in schizophrenia were generated from two prospective phase 3 studies: a noninferiority study comparing the efficacy of PP3M vs. PP1M (study A) ${ }^{18}$ and a primary efficacy study of PP3M (study B). ${ }^{19}$ Subgroup analyses of the noninferiority global study demonstrated the efficacy and safety of PP3M in East Asian ${ }^{21}$ and European populations (unpublished data), which was consistent with the global population. The Hispanic population represents an important ethnic subgroup, with documented differences in pharmacological response to pharmacokinetic and pharmacodynamic factors. ${ }^{22}$ Here, we studied the efficacy and safety of PP3M in Latin American patients with schizophrenia and compared these outcomes with findings for patients from the rest-of-world (ROW) based on a subgroup analysis of study $A$ and $B$.

\section{Methods}

\section{Study design and population}

A subgroup analysis of Latin American patients (Argentina, Brazil, Colombia, and Mexico) was performed with data from two multinational, double-blind (DB), randomized, controlled phase 3 studies (NCT01515423 and NCT01529515). Details of inclusion and exclusion criteria and study design for both primary studies have been described elsewhere. ${ }^{18,19}$ Briefly, patients (men and women aged 18 to 70 years) with schizophrenia (DSMIV-TR criteria), diagnosed for $\geqslant 1$ year before screening, and with Positive and Negative Syndrome Scale (PANSS) score between 70 and 120 were included. Key exclusion criteria were: active DSM-IV diagnosis other than schizophrenia; significant risk of suicidal behavior; history of substance dependence within 6 months before screening; morbid obesity (body mass index $>40 \mathrm{~kg} / \mathrm{m}^{2}$ ), or other systemic disease. ${ }^{18,19}$

In both studies, eligible patients received PP1M during a 17-week open-label (OL) stabilization phase. In study $A$, stable patients (PANSS $<70$, PANSS item [P1, P2, P3, P6, P7, G8, G14] score $\leqslant 4$ and Clinical Global Impression-Severity [CGI-S] score $\geqslant 1$ ) were directly randomized to receive either $\mathrm{PP} 1 \mathrm{M}$ or $\mathrm{PP} 3 \mathrm{M}$ in a 48-week DB treatment phase. ${ }^{18}$ In study $B$, following the OL stabilization phase, patients entered a 12-week OL maintenance phase and received a single dose of PP3M. Stabilized patients were then randomized to either PP3M or placebo in a variable length DB treatment phase. ${ }^{19}$

For both studies, the protocols and their respective amendments were reviewed by an independent ethics committee or institutional review board at each site. The studies were conducted in compliance with the Declaration of Helsinki and applicable regulatory requirements. Written informed consent was obtained from all patients before study enrollment.

\section{Treatment}

During screening, patients without documented tolerability to oral or injectable risperidone or paliperidone received paliperidone extended release (ER) $6 \mathrm{mg}$ tablets for 4 to 6 consecutive days (oral tolerability testing). In the $\mathrm{OL}$ phase, patients received PP1M at the following doses: $150 \mathrm{mg}$ eq. (day 1, deltoid muscle), $100 \mathrm{mg}$ eq. (day 8, deltoid muscle) followed by once-monthly flexible-dose PP1M (50, 75,100 , or $150 \mathrm{mg}$ eq.) on days 36 and 64 (deltoid or gluteal muscle) and same dose as day 64 on day 92 . In the OL maintenance phase of study $B$, patients received a single dose of PP3M at 3.5 times the dose of the final PP1M dose (day 92 of OL phase). ${ }^{19}$ In the DB treatment phase of study $A$, patients received fixed doses of either PP3M at 3.5-fold the dose of PP1M received at week $9(175,263,350$, or $525 \mathrm{mg}$ eq.) or PP1M (50, 75, 100, or $150 \mathrm{mg}$ eq.). Patients in the PP3M group were administered monthly placebo injections (Intralipid, 20\%) to maintain blinding. ${ }^{18}$ In the DB phase of study B, patients received either PP3M (175, 263, 350 , or $525 \mathrm{mg}$ eq.) at the same dose received on day 120 of the OL maintenance phase or placebo (Intralipid, 20\%). ${ }^{19}$

\section{Assessments}

The primary efficacy endpoint for study A was the percentage of patients who remained relapse-free at the end of the 48-week DB phase. For study B, the primary efficacy endpoint was the time from randomization to first relapse event in the DB phase. In both studies, assessment of relapse was based on the definition by Csernansky et al. $^{23}$ (the same criteria used in previous paliperidone ER and PP1M studies).

Secondary efficacy endpoints for both studies included changes from DB baseline to endpoint in PANSS total score, CGI-S, and Personal and Social Performance scale (PSP). The effect of PP3M/PP1M on caregiver burden relative to oral antipsychotics was evaluated based on changes in Involvement Evaluation Questionnaire (IEQ) scores. The IEQ is a 31 -item core module questionnaire to be completed by designated caregivers. ${ }^{24}$

Safety measures comprised recording the rates of treatment emergent adverse events (TEAEs), including serious TEAEs and TEAEs leading to drug withdrawal, clinical laboratory tests (including prolactin and glucose measurements), assessments of body weight, electrocardiograms, and injection-site evaluations.

\section{Statistical analysis}

The sample size determination for each individual study has been described. ${ }^{18,19}$ Both studies were not powered for individual subgroup analysis.

The modified intention-to-treat (mITT) DB analysis set (defined as all patients who entered the DB phase and received $\geqslant 1$ dose of $D B$ drug, without any errors in the delivery of active treatment due to the manufacturing of the investigational product) was used for analysis of the primary and secondary efficacy endpoints from study $A$. For study $B$, all efficacy analyses during $D B$ phase were summarized in the ITT (DB) analysis set that included all 
patients who received $\geqslant 1$ dose of study drug in the $D B$ phase. For both studies, safety during the OL phase was summarized in the ITT OL analysis set that included all patients receiving $\geqslant 1$ dose of study drug in the $\mathrm{OL}$ phase; whereas safety analyses for the DB phase were conducted using the safety analysis set (defined as all patients receiving at least one dose of study drug during the DB phase).

The Kaplan-Meier method was used to estimate the 48week cumulative relapse-free survival rate from study $A$; standard error (SE) estimates were based on Greenwood's formula. For study B, the Kaplan-Meier method was used to estimate time from randomization to the first relapse event in the DB phase and the log-rank test (two-sided) was used for comparison between PP3M and placebo. For both study A and study B, treatment comparisons between PP3M and PP1M or placebo for changes from DB baseline to endpoint in PANSS, PSP, and CGI-S scores were performed using an analysis of covariance model (ANCOVA) with treatment and country as factors and DB baseline score as a covariate. Leastsquare (LS) estimates of the treatment differences and $95 \%$ confidence intervals $(95 \% \mathrm{Cl})$ were reported.

Mirror image analysis was performed to evaluate if caregiver burden was reduced for patients who were switched from oral antipsychotics to PP3M. The analysis was carried out using a mixed model with caregiver burden at OL baseline and DB endpoint as the outcome variable, and with study ID and time points (OL baseline and DB endpoint) included as factors. The analysis was performed using the pooled modified ITT (DB) analysis set (including mITT [DB] analysis set in study A and ITT [DB] analysis set in study B) and was limited only to patients who were taking an oral antipsychotic prior to study entry and who had both OL baseline and DB endpoint IEQ data. The LAI treatment groups (PP1M/PP3M) from both studies were pooled together, including patients from study $B$ who were randomized to placebo in the $D B$ phase, but received PP1M/PP3M in the OL phase.

Descriptive statistics by study phase were used for baseline, demographic, and safety assessment.

\section{Results}

\section{Patient disposition}

\section{Study A}

Of 1,429 patients enrolled and dosed in the OL phase, 87 were recruited from Latin America (Argentina: $n=37$, Brazil: $n=31$, Mexico: $n=19)$. Most patients (71/87 [81.6\%]; PP3M: $n=34$, PP1M: $n=37$ ) from Latin America entered the DB phase. Of these 71 patients, $63(88.7 \%)$ completed the study (PP3M: $n=32$, PP1M: $n=31$ ). A similar percentage of ROW patients ( $\mathrm{mITT}$ [DB] analysis set) entered the DB phase (924/1342 [68.9\%]) and completed the study $(761 / 924[82.5 \%])$.

\section{Study B}

Of 506 patients enrolled and dosed in the OL phase, 69 were recruited from Latin America (Colombia: $n=41$,
Mexico: $n=28)$. In total, 43/69 (62.3\%) patients (PP3M: 21, placebo: $n=22$ ) from Latin America continued in the DB phase, and $38 / 43(88.4 \%)$ patients completed the study (PP3M: $n=18$; placebo: $n=20$ ). A similar percentage of ROW patients entered the DB phase (262/437 [59.9\%]) and completed the study (232/262 [88.5\%]). The most common reason for discontinuations in both studies was withdrawal of consent (Figure 1).

\section{Demographics and baseline characteristics}

Baseline demographic and disease characteristics were generally balanced across treatment groups and similar between patients from Latin America and ROW (Table 1). In the OL phase of both studies, patients from Latin America were predominantly men (study A: 48/87 [55\%], study B: $57 / 69$ [83\%]), with mean age of 40.6 years (study A) and 34.5 years (study B). The DB phase also included mostly men (65\% to $86 \%)$ with similar mean ages ranging from 34.6 to 42.0 years; except for the PP3M group in study A, which included mostly women (20/34 [59\%]). The mean age of schizophrenia diagnosis ranged from 21.4 to 26.9 years and most patients did not have a history of hospitalization for psychosis within 24 months prior to study start. Symptom severity as indicated by baseline PANSS score prior to randomization was similar in the Latin American and ROW subgroups and generally higher in study $A$.

\section{Primary efficacy}

At the end of the 48-week DB treatment phase of study A, the proportion of patients who relapsed was small for patients from Latin America (PP3M: 1/34 [2.9\%], PP1M: none) vs. ROW (PP3M: $37 / 449$ [8.2\%], PP1M: $47 / 475$ [9.9\%]) (Table 2).

The Kaplan-Meier estimate of the difference $(95 \% \mathrm{Cl})$ between the treatment groups (PP3M-PP1M) in the percentage of patients who remained relapse free was $-3 \%(-8.9$ to $2.8 \%)$ in the Latin American subgroup and $1.8 \%(-2.2$ to $5.9 \%)$ in the ROW subgroup; the lower bound of the $95 \% \mathrm{Cl}$ was larger than the pre-specified noninferiority margin of $-15 \%$, suggesting noninferiority of PP3M to PP1M.

In the Latin American subgroup from study $B, 2 / 21$ $(9.5 \%)$ patients from the PP3M group and $3 / 22$ (13.6\%) patients from the placebo group relapsed during the DB phase, and the median time-to-relapse (the time at which the cumulative survival function equals 0.5 [or $50 \%]$ ) was not estimable for either group. The difference in time-to-relapse of schizophrenia symptoms was not significant between PP3M and placebo. In the ROW subgroup, $12 / 139$ (8.6\%) patients from the PP3M group and $39 / 123(31.7 \%)$ patients from the placebo group relapsed. The median time-to-relapse for the placebo group was 395 days and not estimable for the PP3M group. In the ROW subgroup, PP3M significantly $(p<0.001)$ delayed the time to first relapse as compared with placebo (Table 2). 

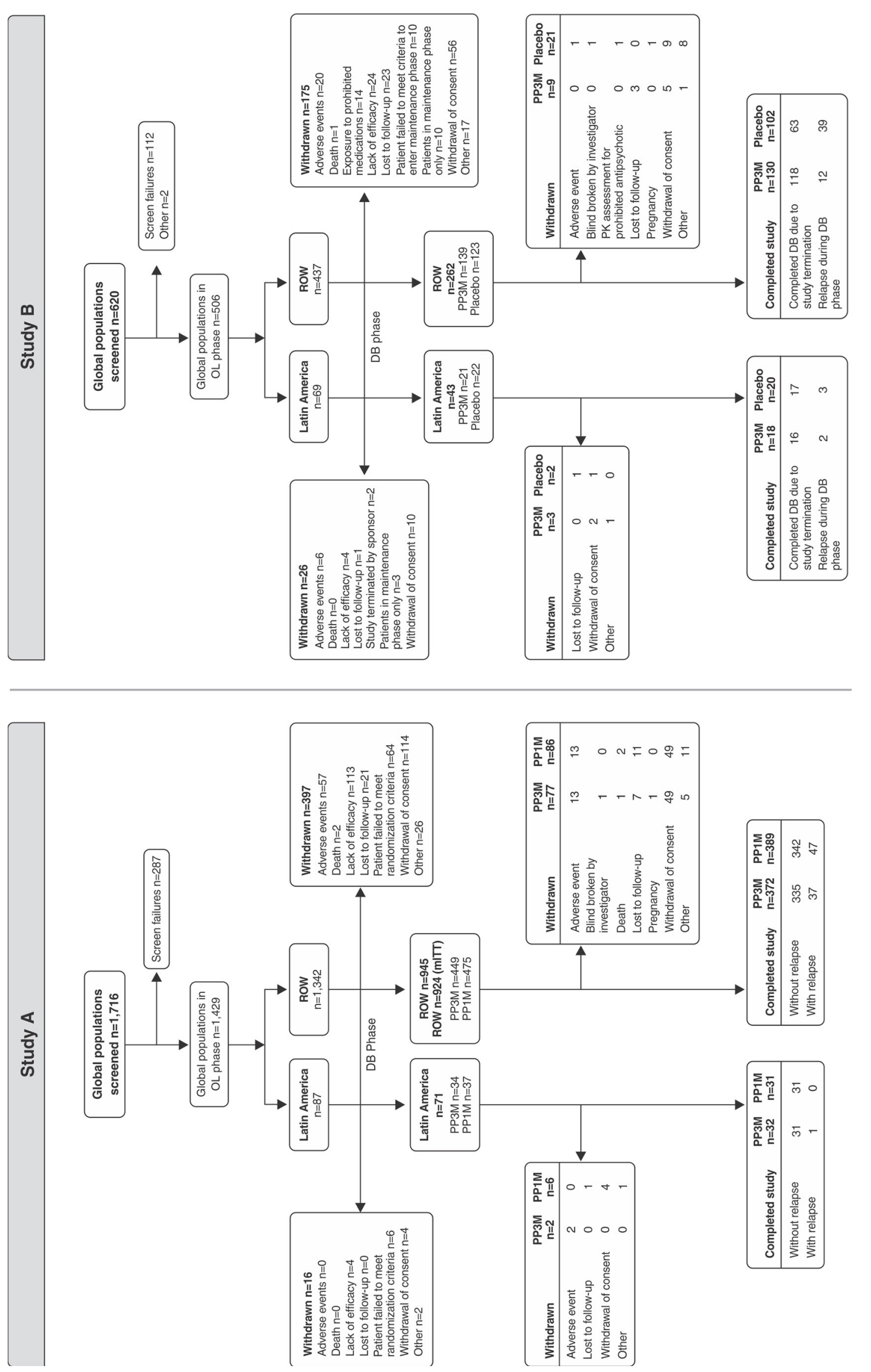

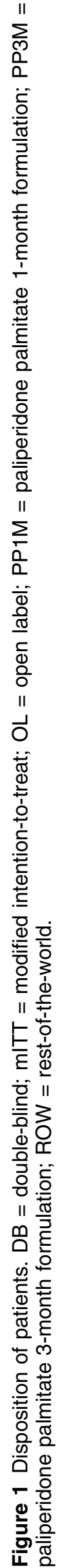




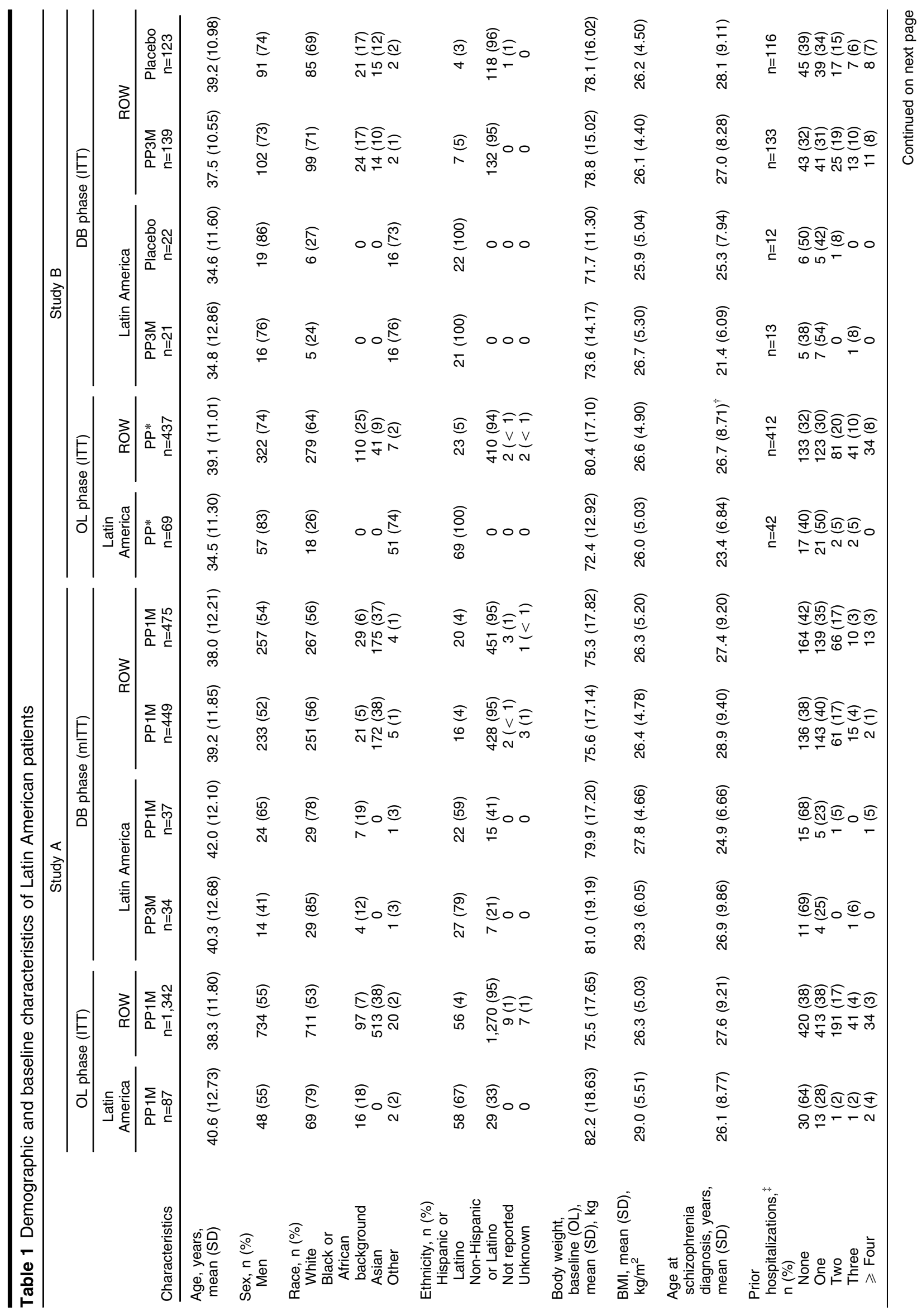


AJ Savitz et al.

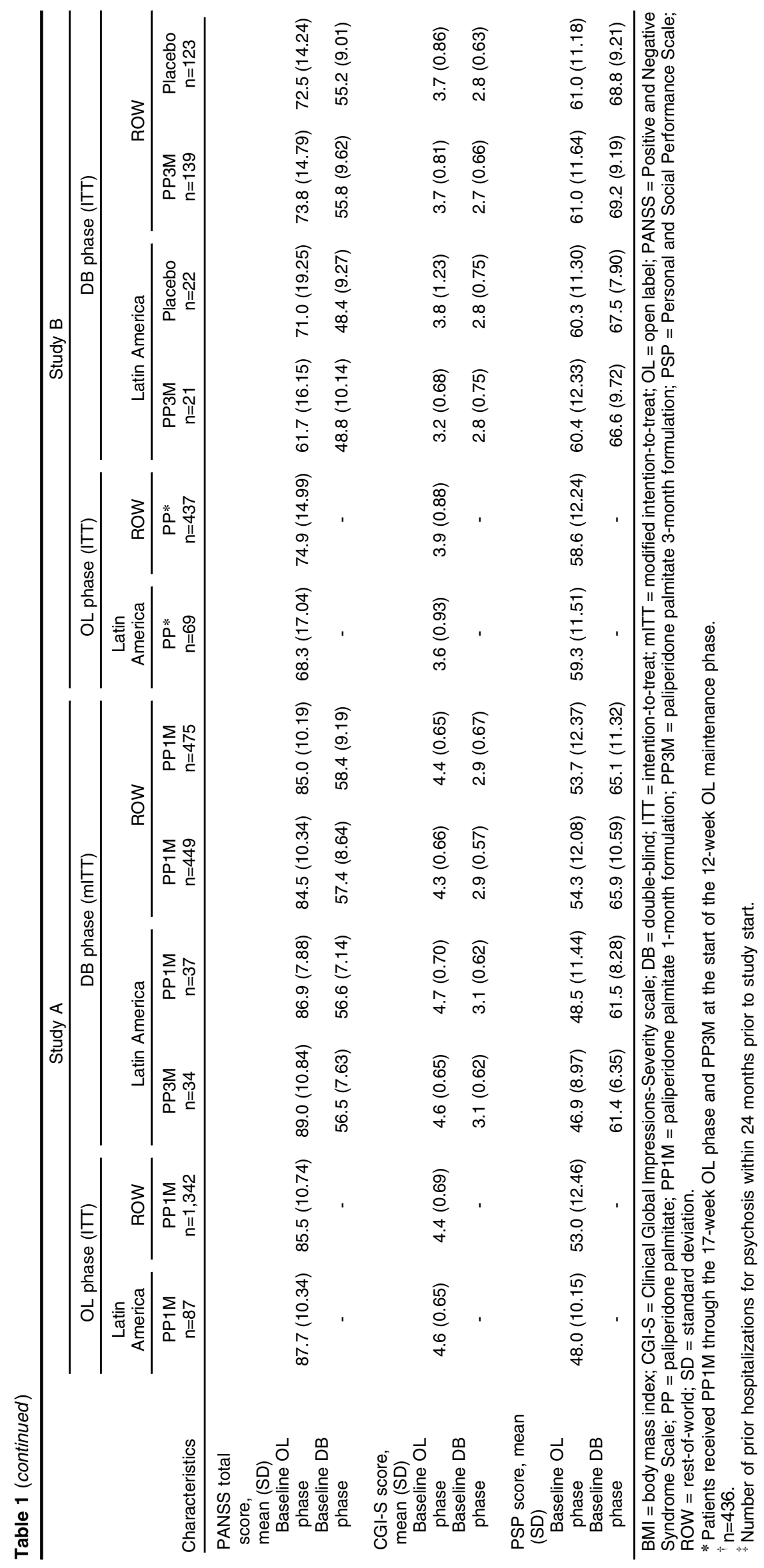


Table 2 Primary efficacy analyses

\begin{tabular}{|c|c|c|c|c|c|c|}
\hline & \multicolumn{6}{|c|}{ Study A: Percentage of patients who remained relapse-free during the DB phase (mITT [DB] analysis set) } \\
\hline & \multicolumn{3}{|c|}{ Latin America } & \multicolumn{3}{|c|}{ ROW } \\
\hline & PP3M & PP1M & Total & PP3M & PP1M & Total \\
\hline Patients assessed, $\mathrm{n}$ & 34 & 37 & 71 & 449 & 475 & 924 \\
\hline Patients censored, n (\%) & $33(97.1)$ & 37 (100.0) & 70 (98.6) & $412(91.8)$ & $428(90.1)$ & $840(90.9)$ \\
\hline Patients relapsed, $\mathrm{n}(\%)$ & $1(2.9)$ & $0(0.0)$ & $1(1.4)$ & $37(8.2)$ & $47(9.9)$ & $84(9.1)$ \\
\hline $\begin{array}{l}\text { Relapse-free* } \\
\text { Week } 48 \text { (DB) }\end{array}$ & & & & & & \\
\hline $\begin{array}{l}\text { Percentage relapse-free } \\
\text { Difference (PP3M-PP1M) } \\
95 \% \mathrm{Cl}\end{array}$ & $\begin{array}{c}97.0 \\
-3.0 \\
(-8.9 \text { to } 2.8)\end{array}$ & 100.0 & & $\begin{array}{c}91.0 \\
1.8 \\
(-2.2 \text { to } 5.9)\end{array}$ & 89.2 & \\
\hline
\end{tabular}

Study B: Time-to-relapse of symptoms of schizophrenia (ITT [DB] analysis set)

\begin{tabular}{|c|c|c|c|c|c|c|}
\hline \multirow[b]{2}{*}{ Descriptive* } & \multicolumn{3}{|c|}{ Latin America } & \multicolumn{3}{|c|}{ ROW } \\
\hline & PP3M & Placebo & Total & PP3M & Placebo & Total \\
\hline Patients assessed, $\mathrm{n}$ & 21 & 22 & 43 & 139 & 123 & 262 \\
\hline Patients censored, $\mathrm{n}(\%)$ & $19(90.5)$ & $19(86.4)$ & $38(88.4)$ & $127(91.4)$ & $84(68.3)$ & $211(80.5)$ \\
\hline No. of events, $\%$ & $2(9.5)$ & $3(13.6)$ & $5(11.6)$ & $12(8.6)$ & 39 (31.7) & $51(19.5)$ \\
\hline $25 \%$ quantile, $95 \% \mathrm{Cl}$ & (34.0 to -$)$ & (51.0 to - ) & (104.0 to -$)$ & - & 127.0 (90.0 to 189.0$)$ & 274.0 (173.0 to -$)$ \\
\hline Median, $95 \% \mathrm{Cl}$ & - & - & - & - & 395.0 (274.0 to -$)$ & (395.0 to - ) \\
\hline $75 \%$ quantile, $95 \% \mathrm{Cl}$ & - & - & - & - & (395.0 to - ) & - \\
\hline$p$-value ${ }^{\dagger}$ & & & 0.778 & & & $<0.001$ \\
\hline$\chi^{2}$ & & & 0.080 & & & 23.308 \\
\hline
\end{tabular}

$95 \% \mathrm{Cl}=95 \%$ confidence interval; $\mathrm{DB}=$ double-blind; ITT = intention-to-treat; $\mathrm{mITT}=$ modified intention-to-treat; OL = open label; PP1M = paliperidone palmitate 1-month formulation; PP3M = paliperidone palmitate 3-month formulation; ROW = rest-of-world.

* Based on Kaplan-Meier product limit estimates.

'Based on log-rank test to compare treatment difference.

\section{Secondary efficacy}

In the Latin American subgroup from study $A$, the mean (standard deviation [SD]) reduction in PANSS total scores and increase in PSP scores at the end of the 48-week DB treatment phase was similar in PP1M (PANSS: -7.0 [15.78]; PSP: 3.9 [11.67]) and PP3M (PANSS: -7.6 [9.43]; PSP: 4.3 [10.54]) groups. In addition, these scores showed higher differences in the Latin American subgroup vs. the ROW subgroup (Table 3). The CGI-S score remained stable through the DB phase and mean (SD) change from DB baseline to endpoint was similar in PP3M and PP1M for both Latin American (PP3M: 0.0 [0.63], PP1M: 0.3 [0.97]) and ROW subgroups (PP3M: -0.1 [0.85], PP1M: -0.1 [0.72]).

In study $B$, mean (SD) PANSS total scores increased from DB baseline in the Latin American (PP3M, 3.6 [11.96]; placebo, 1.8 [11.18]) subgroup, and in ROW placebo patients (7.6 [14.78]), but decreased in ROW PP3M patients (-1.1 [7.53]) (Table 3). Mean (SD) PSP scores showed a greater decrease from DB baseline to endpoint in the Latin American subgroup receiving PP3M $(-2.5[7.86])$ vs. the ROW subgroup $(-0.2$ [6.40]). In the placebo group, smaller mean (SD) decrease in PSP score was noted in the Latin American (-1.5 [8.20]) as compared with the ROW subgroup (-4.7 [9.90]). CGI-S scores remained stable through the DB phase in both Latin American (mean [SD] change from baseline: PP3M, 0.2 [0.60]; placebo: 0.0 [0.53]) and ROW subgroups. For all efficacy measures, no statistically significant difference between PP3M and placebo groups were noted in the
Latin American subgroup (this result should be interpreted with caution considering the small sample size in the Latin American subgroup); however, in the ROW subgroup, a statistically significant difference $(p<0.001)$ favoring PP3M was reported for PANSS total score (LS means difference [SE], -8.7 [1.43]; $95 \% \mathrm{Cl}-11.49$ to -5.86$)$, PSP score (LS means difference [SE], 4.6 [1.03]; $95 \% \mathrm{Cl} 2.58$ to 6.62) and CGI-S score (LS means difference [SE], -0.4 [0.09]; $95 \% \mathrm{Cl}-0.61$ to -0.26$)$.

\section{Caregiver burden}

At OL baseline, the mean (SD) age of caregivers from Latin America was 53.1 (12.33) years in both studies $(n=156)$. Most caregivers were parents $(78[50 \%])$ or siblings (43 [28\%]), and paid caregivers were excluded from the analysis. Most caregivers (105 [68\%]) spent more than 32 hours with the patient during the past four weeks.

\section{Mirror image analysis}

Mean (SD) change in IEQ total scores (-9.4 [15.16]) from OL baseline (pre-switch) to DB endpoint (post-switch) suggested significant attenuation $(p<0.001)$ in overall caregiver burden in patients who switched from oral antipsychotics (prior to study entry) to LAI (during the study) (Table 4). Mean (SD) changes in number of work days missed by caregivers over the past 4 weeks (-5.6 [11.19]) and number of leisure days of caregivers impacted over 
Table 3 Change in secondary efficacy endpoints during the DB phase

\begin{tabular}{|c|c|c|c|c|c|c|}
\hline \multirow[b]{4}{*}{$\begin{array}{l}\text { Efficacy } \\
\text { measure }\end{array}$} & \multicolumn{6}{|c|}{ Study A (mITT [DB] analysis set) } \\
\hline & \multicolumn{3}{|c|}{ Latin America } & \multicolumn{3}{|c|}{ ROW } \\
\hline & \multicolumn{2}{|c|}{$\begin{array}{c}\text { Mean (SD) change from DB } \\
\text { baseline to } D B \text { endpoint }\end{array}$} & \multirow[b]{2}{*}{$\begin{array}{l}\text { Between group difference } \\
\text { - LS mean (SE) [95\%Cl]* }\end{array}$} & \multicolumn{2}{|c|}{$\begin{array}{c}\text { Mean (SD) change from DB } \\
\text { baseline to DB endpoint }\end{array}$} & \multirow[b]{2}{*}{$\begin{array}{l}\text { Between group difference } \\
\text { - LS mean (SE) [95\%Cl]* }\end{array}$} \\
\hline & $\begin{array}{l}\text { PP3M } \\
(n=34)\end{array}$ & PP1M (n=37) & & $\begin{array}{l}\text { PP3M } \\
(n=449)\end{array}$ & PP1M (n=475) & \\
\hline \multirow[t]{4}{*}{$\begin{array}{l}\text { PANSS total } \\
\text { score } \\
\text { CGI-S score } \\
\text { PSP score }\end{array}$} & $\begin{array}{l}-7.6(9.43) \\
0.0(0.63) \\
4.3(10.54)\end{array}$ & $\begin{array}{c}-7.0(15.78)^{\dagger} \\
0.3(0.97)^{\dagger} \\
3.9(11.67)^{\dagger}\end{array}$ & $\begin{array}{l}-0.0(3.04)[-6.08 \text { to } 6.07] \\
-0.2(0.18)[-0.53 \text { to } 0.17] \\
0.2(2.59)[-5.02 \text { to } 5.34]\end{array}$ & $\begin{array}{l}-3.2(12.66)^{\ddagger} \\
-0.1(0.85)^{\ddagger} \\
1.1(10.17)^{\oplus}\end{array}$ & $\begin{array}{l}-4.1(11.42)^{\S} \\
-0.1(0.72)^{\mid l} \\
1.8(8.99)^{\star \star}\end{array}$ & $\begin{array}{c}0.9(0.78)[-0.59 \text { to } 2.45] \\
0.1(0.05)[-0.04 \text { to } 0.15] \\
-0.6(0.62)[-1.82 \text { to } 0.60]\end{array}$ \\
\hline & \multicolumn{6}{|c|}{ Study B (ITT [DB] analysis set) } \\
\hline & \multicolumn{3}{|c|}{ Latin America } & \multicolumn{3}{|c|}{ ROW } \\
\hline & $\begin{array}{l}\text { PP3M } \\
(\mathrm{n}=21)\end{array}$ & $\begin{array}{c}\text { Placebo } \\
(n=22)\end{array}$ & $\begin{array}{l}\text { Between group difference } \\
\text { - LS mean (SE) [95\%Cl]* }\end{array}$ & $\begin{array}{l}\text { PP3M } \\
(n=139)\end{array}$ & $\begin{array}{l}\text { Placebo } \\
(n=123)\end{array}$ & $\begin{array}{l}\text { Between group difference } \\
\text { - LS mean (SE) }[95 \% \mathrm{Cl}]^{*}\end{array}$ \\
\hline $\begin{array}{l}\text { PANSS total } \\
\text { score }\end{array}$ & $3.6(11.96)$ & $1.8(11.18)$ & $1.5(3.55)[-5.69$ to 8.69$]$ & $-1.1(7.53)^{\dagger \dagger}$ & $7.6(14.78)^{\text {林 }}$ & $-8.7(1.43)[-11.49$ to -5.86$]$ \\
\hline $\begin{array}{l}\text { p-value* } \\
\text { CGI-S score } \\
\text { p-value* }\end{array}$ & $0.2(0.60)$ & $\begin{array}{c}0.675 \\
0.0(0.53) \\
0.314\end{array}$ & $0.2(0.17)[-0.17$ to 0.53$]$ & $0.1(0.59)^{\dagger \dagger}$ & $\begin{array}{l}<0.001 \\
0.5(0.90)+1 \\
<0.001\end{array}$ & $-0.4(0.09)[-0.61$ to -0.26$]$ \\
\hline $\begin{array}{l}\text { PSP score } \\
\text { p-value* }\end{array}$ & $-2.5(7.86)$ & $\begin{array}{l}-1.5(8.20) \\
0.740\end{array}$ & $-0.8(2.52)[-5.95$ to 4.26$]$ & $-0.2(6.40)^{\S \S}$ & $\begin{aligned}-4.7 & (9.90)^{+1} \\
< & 0.001\end{aligned}$ & $4.6(1.03)$ [2.58 to 6.62$]$ \\
\hline
\end{tabular}

$95 \% \mathrm{Cl}=95 \%$ confidence interval; CGI-S = clinical global impression-severity scale; $\mathrm{DB}=$ double-blind; ITT = intention-to-treat set; $\mathrm{mITT}=$ modified intention-to-treat set; LS mean = least square mean; PANSS = positive and negative syndrome scale; PSP = personal and social performance; PP1M = paliperidone palmitate 1-month formulation; PP3M = paliperidone palmitate 3-month formulation; ROW = rest-of-world; $\mathrm{SD}=$ standard deviation; $\mathrm{SE}=$ standard error.

* Based on analysis of covariance (ANCOVA) model with country and treatment as factors and baseline values as covariates. Difference in change from baseline was determined as PP3M-PP1M/PPP3M-placebo.

${ }^{\dagger} n=36,{ }^{\dagger} n=447,{ }^{\S} n=467,{ }^{\prime \prime} n=468,{ }^{`} n=440,{ }^{* *} n=459,{ }^{\dagger \dagger} n=138,{ }^{*} n=120,{ }^{\S \S} n=136$.

Table 4 Mirror image comparison (oral antipsychotic [prior to study entry] vs. long-acting injectable antipsychotics [during the study]) in the Latin American subgroup pooled modified ITT (DB) analysis set

\begin{tabular}{lccccc}
\hline Outcome variable & $\mathrm{n}$ & OL baseline & DB endpoint & Change from baseline & $\mathrm{p}$-value \\
\hline IEQ total score & 84 & $36.2(15.89)$ & $26.8(13.87)$ & $-9.4(15.16)$ & $<0.001^{*}$ \\
Number of work days missed & 5 & $8.0(9.72)$ & $2.4(3.13)$ & $-5.6(11.19)$ & Not provided $^{\dagger}$ \\
Number of leisure days impacted in last 4 weeks & 59 & $2.8(6.18)$ & $2.0(7.21)$ & $-0.8(9.66)$ & $0.4956^{*}$ \\
Number of hours spent caregiving in last 7 days & 60 & $45.2(42.13)$ & $58.2(54.56)$ & $13.0(45.38)$ & $0.0306^{*}$ \\
\hline
\end{tabular}

Data presented as mean (standard deviation).

$\mathrm{DB}=$ double-blind; IEQ = Involvement Evaluation Questionnaire; ITT = intention-to-treat; OL = open-label.

* Mixed model with IEQ total score, number of leisure days impacted, or number of hours spent caregiving collected at baseline (OL) and end point (DB) as the outcome variable, and study ID and time points (baseline [OL] and endpoint [DB]) as factors. ${ }^{\dagger} p$-value not provided because of the small numbers of patients.

the past 4 weeks $(-0.8[9.66])$ also indicate reduced caregiver burden. An increase was noted in the number of hours spent caregiving over the past 7 days (13.0 [45.38]).

\section{Safety}

During the OL phase, 846/1,429 (59.2\%) patients from study A (Latin America, 40/87 [46\%]; ROW, 806/1,342 [60.1\%]), and 330/506 (65.2\%) patients from study B (Latin America, 47/69 [68.1\%]; ROW, 283/437 [64.8\%]) experienced $\geqslant 1$ TEAEs (Table 5 ). In the Latin American subgroup, $1 / 87(1.1 \%)$ patient from study $A$ (ROW: $100 /$ $1,342[7.5 \%])$ and $6 / 69(8.7 \%)$ patients from study $B$ had $\geqslant 1$ serious TEAE (ROW, $27 / 437$ [6.2\%]). No early study discontinuations due to TEAEs were reported in Latin
American patients during the OL phase of study A (ROW, $60[4.5 \%]$ ), whereas $6 / 69(8.7 \%)$ patients discontinued due to TEAEs during the OL phase of study B (ROW, 20/ $437[4.6 \%])$.

Overall, 682/976 (69.9\%) patients from study A (Latin America: PP3M, 24/34 [70.6\%]; PP1M, 23/37 [62.2\%]) and 183/305 (60\%) patients from study B (Latin America: PP3M, 15/21 [71.4\%]; placebo, 12/22 [54.5\%]) experienced $\geqslant 1$ TEAE during the DB phase. Frequency of TEAEs in the PP3M group during the DB phase was consistent in the Latin American and ROW subgroups (study A: 318/470 [67.7\%]; study B: 84/139 [60.4\%]). Frequent TEAEs ( $\geqslant 5 \%$ patients in any treatment group) in the Latin American subgroup receiving PP3M that were common to study $A$ and $B$ included: urinary tract 


\begin{tabular}{|c|c|c|c|c|c|c|}
\hline & \multicolumn{6}{|c|}{ Study A } \\
\hline & \multicolumn{2}{|c|}{ OL phase (ITT OL analysis set) } & \multicolumn{4}{|c|}{ DB phase (safety analysis set) } \\
\hline & Latin America & ROW & Latin America & ROW & Latin America & ROW \\
\hline & $\begin{array}{l}\mathrm{PP} 1 \mathrm{M} \\
(\mathrm{n}=87)\end{array}$ & $\begin{array}{c}\mathrm{PP} 1 \mathrm{M} \\
(\mathrm{n}=1,342)\end{array}$ & $\begin{array}{l}\text { PP3M } \\
(\mathrm{n}=34)\end{array}$ & $\begin{array}{c}\text { PP3M } \\
(n=470)\end{array}$ & $\begin{array}{l}\mathrm{PP} 1 \mathrm{M} \\
(\mathrm{n}=37)\end{array}$ & $\begin{array}{c}\mathrm{PP} 1 \mathrm{M} \\
(\mathrm{n}=475)\end{array}$ \\
\hline Patients with $\geqslant 1$ TEAEs & $40(46.0)$ & $806(60.1)$ & $24(70.6)$ & $318(67.7)$ & $23(62.2)$ & $317(66.7)$ \\
\hline TEAE leading to drug withdrawal* & 0 & $60(4.5)$ & $2(5.9)$ & $13(2.8)$ & 0 & $13(2.7)$ \\
\hline Patients with $\geqslant 1$ serious TEAE & $1(1.1)$ & $100(7.5)$ & $1(2.9)$ & $25(5.3)$ & 0 & $37(7.8)$ \\
\hline TEAEs leading to death & 0 & $2(0.1)$ & 0 & $1(0.2)$ & 0 & $3(0.6)$ \\
\hline \multicolumn{7}{|l|}{$\begin{array}{l}\text { TEAEs reported in } \geqslant 5 \% \\
\text { of patients in any group }\end{array}$} \\
\hline Influenza & $3(3.4)$ & $12(0.9)$ & $2(5.9)$ & $4(0.9)$ & $2(5.4)$ & $7(1.5)$ \\
\hline Urinary tract infection & $1(1.1)$ & $8(0.6)$ & $2(5.9)$ & $3(0.6)$ & $1(2.7)$ & $3(0.6)$ \\
\hline Headache & $2(2.3)$ & $44(3.3)$ & $2(5.9)$ & $16(3.4)$ & $1(2.7)$ & $25(5.3)$ \\
\hline Fatigue & $1(1.1)$ & $16(1.2)$ & $2(5.9)$ & $8(1.7)$ & 0 & $5(1.1)$ \\
\hline Bronchitis & 0 & $3(0.2)$ & $1(2.9)$ & $3(0.6)$ & $2(5.4)$ & $5(1.1)$ \\
\hline Anxiety & $1(1.1)$ & $82(6.1)$ & $1(2.9)$ & $26(5.5)$ & $2(5.4)$ & $22(4.6)$ \\
\hline Insomnia & $2(2.3)$ & $94(7.0)$ & $1(2.9)$ & $15(3.2)$ & $2(5.4)$ & $22(4.6)$ \\
\hline Somnolence & $5(5.7)$ & $24(1.8)$ & $1(2.9)$ & $4(0.9)$ & 0 & $5(1.1)$ \\
\hline Toothache & $1(1.1)$ & $15(1.1)$ & 0 & $3(0.6)$ & $2(5.4)$ & $4(0.8)$ \\
\hline Nasopharyngitis & 0 & $66(4.9)$ & 0 & $36(7.7)$ & 0 & $33(6.9)$ \\
\hline \multicolumn{7}{|l|}{ Weight gain-related TEAEs } \\
\hline Weight increase & $9(10.3)$ & $55(4.1)$ & $9(26.5)$ & $96(20.4)$ & $6(16.2)$ & $103(21.7)$ \\
\hline \multicolumn{7}{|l|}{ EPS-related TEAEs } \\
\hline Akathisia & 0 & $82(6.1)$ & $1(2.9)$ & $19(4.0)$ & $3(8.1)$ & $11(2.3)$ \\
\hline \multicolumn{7}{|l|}{ Prolactin-related TEAEs } \\
\hline Amenorrhea & $5(5.7)$ & $12(0.9)$ & 0 & $8(1.7)$ & 0 & $4(0.8)$ \\
\hline \multicolumn{7}{|l|}{ Injection site-related TEAEs } \\
\hline Injection site pain & $2(2.3)$ & $125(9.3)$ & 0 & $12(2.6)$ & $1(2.7)$ & $13(2.7)$ \\
\hline \multicolumn{7}{|l|}{$\begin{array}{l}\text { Diabetes mellitus and } \\
\text { hyperglycemia-related TEAEs }\end{array}$} \\
\hline \multirow[t]{3}{*}{ Hyperglycemia } & $2(2.3)$ & $1(0.1)$ & 0 & $4(0.9)$ & $3(8.1)$ & $7(1.5)$ \\
\hline & \multicolumn{6}{|c|}{ Study B } \\
\hline & $\begin{array}{c}\mathrm{PP}^{\dagger} \\
(\mathrm{n}=69)\end{array}$ & $\begin{array}{c}\mathrm{PP}^{\dagger} \\
(\mathrm{n}=437)\end{array}$ & $\begin{array}{l}\text { PP3M } \\
(n=21)\end{array}$ & $\begin{array}{c}\text { PP3M } \\
(n=139)\end{array}$ & $\begin{array}{c}\text { Placebo } \\
(n=22)\end{array}$ & $\begin{array}{l}\text { Placebo } \\
(n=123)\end{array}$ \\
\hline Patients with $\geqslant 1$ TEAEs & $47(68.1)$ & $283(64.8)$ & $15(71.4)$ & $84(60.4)$ & $12(54.5)$ & $72(58.5)$ \\
\hline TEAE leading to drug withdrawal* & $6(8.7)$ & $20(4.6)$ & 0 & 0 & 0 & $1(0.8)$ \\
\hline Patients with $\geqslant 1$ serious TEAE & $6(8.7)$ & $27(6.2)$ & $1(4.8)$ & $3(2.2)$ & $1(4.5)$ & $14(11.4)$ \\
\hline TEAEs leading to death & 0 & $1(0.2)$ & 0 & 0 & 0 & 0 \\
\hline \multicolumn{7}{|l|}{$\begin{array}{l}\text { TEAEs reported in } \geqslant 5 \% \\
\text { patients in any group }\end{array}$} \\
\hline Urinary tract infection & $2(2.9)$ & 0 & $3(14.3)$ & $2(1.4)$ & $2(9.1)$ & 0 \\
\hline Headache & $3(4.3)$ & $30(6.9)$ & $2(9.5)$ & $12(8.6)$ & $2(9.1)$ & $4(3.3)$ \\
\hline Influenza & $4(5.8)$ & $1(0.2)$ & $2(9.5)$ & $1(0.7)$ & $2(9.1)$ & $1(0.8)$ \\
\hline Schizophrenia & $3(4.3)$ & $13(3.0)$ & $1(4.8)$ & $1(0.7)$ & $2(9.1)$ & $13(10.6)$ \\
\hline Anxiety & $3(4.3)$ & $41(9.4)$ & $1(4.8)$ & $12(8.6)$ & $1(4.5)$ & $15(12.2)$ \\
\hline Nasopharyngitis & $2(2.9)$ & $12(2.7)$ & $1(4.8)$ & $8(5.8)$ & 0 & $2(1.6)$ \\
\hline Psychotic disorder & $5(7.2)$ & $10(2.3)$ & $1(4.8)$ & 0 & 0 & 0 \\
\hline Insomnia & $3(4.3)$ & $47(10.8)$ & 0 & $11(7.9)$ & $2(9.1)$ & $15(12.2)$ \\
\hline Weight decrease & $1(1.4)$ & $7(1.6)$ & 0 & $2(1.4)$ & $2(9.1)$ & $9(7.3)$ \\
\hline Suicidal ideation & $4(5.8)$ & $10(2.3)$ & 0 & 0 & $1(4.5)$ & $2(1.6)$ \\
\hline Somnolence & $5(7.2)$ & $10(2.3)$ & 0 & $1(0.7)$ & 0 & 0 \\
\hline Vomiting & $4(5.8)$ & $5(1.1)$ & 0 & 0 & 0 & 0 \\
\hline \multicolumn{7}{|l|}{ EPS-related TEAEs } \\
\hline Akathisia & $7(10.1)$ & $10(2.3)$ & $2(9.5)$ & $5(3.6)$ & 0 & $1(0.8)$ \\
\hline
\end{tabular}




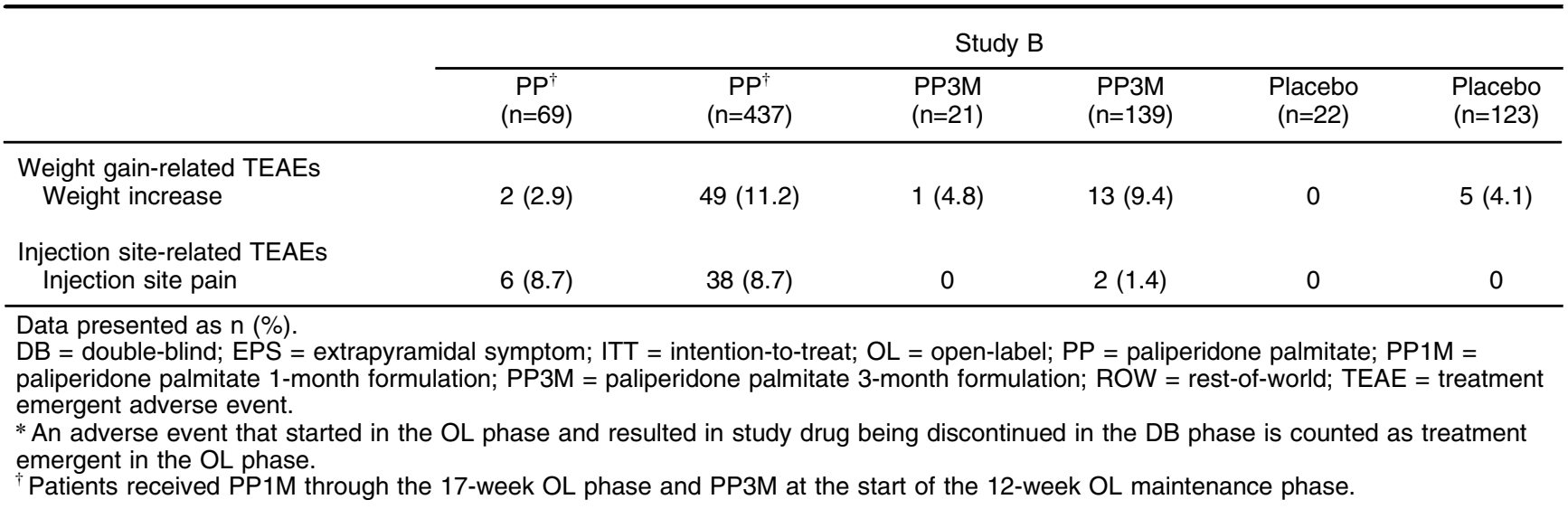

infections (2/34 [5.9\%] and $3 / 21$ [14.3\%]), headache $(2 / 34$ [5.9\%] and 2/21 [9.5\%]), influenza (2/34 [5.9\%] and 2/21 [9.5\%]) and anxiety (1/34 [2.9\%] and 1/21 [4.8\%]). Increase in body weight was the most common weight-gain related TEAE (study A, 9/34 [26.5\%]; study B, 1/21 [4.8\%]) in Latin American patients receiving $\mathrm{PP} 3 \mathrm{M}$; the rates were consistent with those recorded for ROW (study A, 96/470 [20.4\%]; study B, 13/139 [9.4\%]). Among EPS-related TEAEs, akathisia was common in the PP3M group; similar rates were reported in the Latin American (study $A, 1 / 34$ [2.9\%]; study B, 2/21 [9.5\%]) and ROW subgroups (study A: $19 / 470$ [4\%]; study B: 5/139 [3.6\%]). No patients from Latin America receiving PP3M during the DB phase from either study experienced prolactin-related, diabetes mellitus/hyperglycemia-related, or injection-site related TEAEs. A total of $18(1.8 \%)$ patients from study A (Latin America: PP3M, 2/34 [5.9\%]; PP1M, 0; ROW: PP3M, 13/470 [2.8\%], PP1M, 13/475 [2.7\%]) and one (0.3\%) patient from study $B$ (Latin America: 0) discontinued early from the DB phase. Percentage of patients experiencing $\geqslant 1$ serious TEAE was low in the PP3M groups from study A (Latin America, 1/34 [2.9\%]; ROW, 25/403 [5.3\%]) and study B (Latin America, 1/21 [4.8\%]; ROW, 3/139 [2.2\%]). Of the total seven deaths reported in both studies (study $A: n=6$, study $B: n=1)$, none occurred in the Latin American subgroup. ${ }^{18,19}$

\section{Discussion}

The present subgroup analysis explored the efficacy and safety of PP3M in patients with schizophrenia from Latin America compared to ROW. Although some differences were noted (e.g., changes in secondary endpoints, rates of certain TEAEs), the overall efficacy and safety findings were consistent with those observed in the global cohort.

In study A, nearly $90 \%$ of patients from Latin America and ROW who received either LAI treatment (PP3M or $\mathrm{PP} 1 \mathrm{M})$ remained relapse-free and completed the 48week DB phase. Patients from Latin American and ROW in both treatment groups achieved clinically meaningful improvements in psychotic symptoms (PANSS total scores) along with improvements in treatment response (CGI-S) and psychosocial functioning (PSP score) during the study. In study $B$, more than $90 \%$ of patients receiving PP3M from both Latin America and ROW remained relapse-free, and the median time-to-relapse was not estimable. It is noteworthy that the randomized withdrawal design of study B simulates sudden treatment discontinuation that is commonly encountered in routine clinical practice, and these results therefore suggest that patients at such risk could potentially benefit from PP3M. ${ }^{19}$ Changes in secondary efficacy parameters suggested that patients from both subgroups on PP3M treatment had a stable symptomatic and functional status through the DB phase.

Nonadherence to medication is an impediment in the management of schizophrenia. The rate of nonadherence in Latin America is approximately $20 \%$ and younger women are regarded to be at greater risk. This observation is in accordance with available literature that reports overall nonadherence rates of 20 to $80 \%$ and higher occurrence in younger individuals. ${ }^{25}$ Extended dosing interval and reduced number of injections (only four injections per year) with PP3M may potentially improve treatment acceptance, alleviating nonadherence. ${ }^{19}$ The reduced dosing frequency may also be beneficial for patients with limited access to healthcare facilities, in addition to providing a larger window for clinicians to monitor treatment progress and manage impending relapses and more time for vocational rehabilitation and functional recovery. ${ }^{18,26,27}$ Overall, maintenance treatment of schizophrenia with PP3M was clinically effective in preventing relapse and achieving symptom control. These findings are substantially consistent with the efficacy reported for PP1M in global populations. ${ }^{9,11-13,15}$

In a recent post-hoc analysis, $50 \%$ of patients who withdrew PP3M treatment had a relapse-free stability of 13 months following discontinuation. This was associated with the longer half-life of PP3M as compared with oral paliperidone (relapse-free period: 2 months) and PP1M (relapse-free period: 6 months) ${ }^{28}$ Since treatment interruptions during long-term antipsychotic therapy are frequent and unpredictable, durable relapse-prevention with PP3M is clinically desirable; longer stability extends the time available to clinicians and caregivers to ensure continued follow-up and treatment restart. ${ }^{18,19,28}$ PP3M treatment was also associated with high symptomatic remission rates $(\sim 50 \%)$ in patients with schizophrenia. This was accompanied by consistent improvements in total PSP scores and in individual PSP domain scores 
(socially useful activities, personal and social relationships, self-care, and disturbing and aggressive behavior). ${ }^{27}$ In addition, a large number of patients (46\%) continued to have good functioning (PSP total score $>70$ ) from post-stabilized baseline through the completion of the 48-week treatment phase, suggesting sustained, relevant improvements in personal and social functioning. ${ }^{19}$ Taken together, these findings indicate that long-term therapy with PP3M can provide symptomatic and functional remission, regarded as important indices of treatment success and reflect meaningful improvement in quality of life. ${ }^{19,27,29}$ Further, based on observations from the present analysis and on the recently reported East Asian subgroup analysis, the low relapse rates and efficacy of PP3M in delaying relapse and improving psychotic symptoms were consistent with those noted in the global population and independent of regional and ethnic differences. ${ }^{18,19,21}$

The significant improvement in IEQ total score in the Latin American subgroup suggests meaningful alleviation in caregiver burden with PP3M treatment in patients who switched to PP3M from oral antipsychotics. The decreases in work days missed and in the number of leisure days impacted reflect the advantage of PP3M over oral antipsychotics in reducing caregiver burden. These findings support the results from larger global data pooled from the same DB, randomized phase 3 studies. ${ }^{30}$ Improvements in caregiver burden with PP3M can be extrapolated to the drug's efficacy in achieving symptom stability. Also, the formulation benefit of reduced dosing frequency could potentially allow more time for the caregivers to address other issues, such as managing side effects and exploring psychosocial interventions (e.g., psychoeducation, cognitive rehabilitation etc.) as a component of care, and also to pay more attention to their own well-being. ${ }^{30,31}$

Notably, most caregivers in the present analysis were parents or siblings, as is usually the case in Latin America, where most caregivers of adult schizophrenia patients are family members who live with the patient. ${ }^{32}$ It has been suggested that management of schizophrenia should also focus on the mental health of caregivers, and that caregiver burden is a mediator of patient symptomatic status and recovery. ${ }^{32}$ Thus, meaningful reduction in the burden of Latino caregivers of patients on PP3M treatment suggest that the intervention may be useful to alleviate distress among caregivers.

The rates and nature of TEAEs were generally similar in the Latin American and ROW subgroups, and consistent with the known profile of paliperidone. ${ }^{18,19}$ In the East Asian subgroup analysis of study $\mathrm{A}$, the incidence of TEAEs was generally higher than in the global population (81 vs. $68 \%$ ), while in a European subgroup analysis of the same study, TEAE rates were lower than in the nonEuropean population (56 vs. $80 \%$ ). The rates of study discontinuation and serious TEAEs in the Latin American subgroup were low and comparable to those of the entire global cohort. Among clinically relevant TEAEs, the incidence of weight gain-related and EPS-related TEAEs was within observed limits from previous studies. ${ }^{18,19,33,34}$ In the present analysis, none of the patients from Latin America reported prolactin-related, diabetes mellitus/ hyperglycemia-related, or injection-site related TEAEs. Overall, no new safety concerns were identified in patients from Latin America.

The present study has limitations that need to be addressed. The post-hoc nature of this analysis should be taken into account while interpreting the results. The two phase 3 studies from which the data were derived excluded patients with severe psychiatric conditions and hospitalizations, thereby restricting the generalizability of the findings. ${ }^{18,19}$ Also, patients with a recent history of substance dependence, a vulnerable group with dual disorder that is especially important in the Latin American context, were excluded ${ }^{35}$ Enrollment in the DB phase in both studies was based on the principle of enrichment (study A: patients responsive to paliperidone palmitate and study B: patients clinically stable on PP3M), which might explain at least in part the high rates of completion and the low rates of relapse; thus, these positive outcomes might not be directly related to the efficacy of PP3M in the DB phase. ${ }^{18,19}$ Interpretation of the pooled data for caregiver burden should consider that the two studies had different duration, since study $\mathrm{B}$ was terminated early following positive interim analysis results (study A: 17 weeks of OL phase followed by 48 week of DB phase; study B: 17 weeks of OL transition phase, 12 weeks of $\mathrm{OL}$ maintenance phase and variable-length DB phase). Further, reduction in caregiver burden could be associated with improvements in the worrying and urging domains among caregivers (observed in the global population $)^{30}$ since the medication dosing and schedules were being monitored during the study. The study had a small number of patients from Latin America and was not adequately powered to detect a difference between the groups. Furthermore, because patients from only four countries (Argentina, Brazil, Colombia, and Mexico) were included, the group may not be truly representative of the entire Latin American population.

In conclusion, the present subgroup analyses demonstrated that PP3M was effective in preventing relapses and improving psychotic symptoms in patients with schizophrenia from Latin America. No new safety issues unique to the Latin American population with respect to the use of PP3M were identified. Overall, the efficacy and safety profile of PP3M in the Latin American subgroup was consistent with those reported for the global patient population. These data support the use of PP3M as maintenance therapy for schizophrenia in patients from Latin America. Prospective studies in larger populations are warranted to further validate these results.

\section{Acknowledgements}

The authors thank Priya Ganpathy, MPharm, International Society for Medical Publication Professionals (ISMPP) and Certified Medical Publication Professional ${ }^{\mathrm{TM}}$ (CMPP $^{\mathrm{IM}}$ ) (SIRO Clinpharm Pvt. Ltd, Thane, India), for writing assistance, and Ellen Baum, PhD (Janssen Global Services, LLC), for additional editorial assistance. The authors also thank the study participants, without whom these studies would not have been accomplished, and the investigators, for their participation in this study. 
The study was supported by funding from Janssen Research \& Development, LLC. The sponsor also provided funding for development of this manuscript.

\section{Disclosure}

AJS, HX, SG, IN, and MM are employees and shareholders of Janssen Research \& Development, LLC, USA (parent company Johnson \& Johnson). BS is an employee and shareholder of Janssen-Cilag UK.

\section{References}

1 Almond S, Knapp M, Francois C, Toumi M, Brugha T. Relapse in schizophrenia: costs, clinical outcomes and quality of life. Br J Psychiatry. 2004;184:346-51.

2 Emsley R, Chiliza B, Asmal L. The evidence for illness progression after relapse in schizophrenia. Schizophr Res. 2013;148:117-21.

3 Alphs L, Nasrallah HA, Bossie CA, Fu DJ, Gopal S, Hough D, et al. Factors associated with relapse in schizophrenia despite adherence to long-acting injectable antipsychotic therapy. Int Clin Psychopharmacol. 2016;31:202-9.

4 Brissos S, Veguilla MR, Taylor D, Balanza-Martinez V. The role of long-acting injectable antipsychotics in schizophrenia: a critical appraisal. Ther Adv Psychopharmacol. 2014;4:198-219.

5 Agid O, Foussias G, Remington G. Long-acting injectable antipsychotics in the treatment of schizophrenia: their role in relapse prevention. Expert Opin Pharmacother. 2010;11:2301-17.

6 Citrome L. New second-generation long-acting injectable antipsychotics for the treatment of schizophrenia. Expert Rev Neurother. 2013:13:767-83.

7 Greene M, Yan T, Chang E, Hartry A, Touya M, Broder MS. Medication adherence and discontinuation of long-acting injectable versus oral antipsychotics in patients with schizophrenia or bipolar disorder. $\mathrm{J}$ Med Econ. 2018;21:127-34.

8 Leucht C, Heres S, Kane JM, Kissling W, Davis JM, Leucht S. Oral versus depot antipsychotic drugs for schizophrenia--a critical systematic review and meta-analysis of randomised long-term trials. Schizophr Res. 2011;127:83-92.

9 Gopal S, Hough DW, Xu H, Lull JM, Gassmann-Mayer C, Remmerie $\mathrm{BM}$, et al. Efficacy and safety of paliperidone palmitate in adult patients with acutely symptomatic schizophrenia: a randomized, double-blind, placebo-controlled, dose-response study. Int Clin Psychopharmacol. 2010;25:247-56.

$10 \mathrm{Li} \mathrm{H}$, Turkoz I, Zhang F. Efficacy and safety of once-monthly injection of paliperidone palmitate in hospitalized Asian patients with acute exacerbated schizophrenia: an open-label, prospective, noncomparative study. Neuropsychiatr Dis Treat. 2016;12:15-24.

11 Pandina GJ, Lindenmayer JP, Lull J, Lim P, Gopal S, Herben V, et al. A randomized, placebo-controlled study to assess the efficacy and safety of 3 doses of paliperidone palmitate in adults with acutely exacerbated schizophrenia. J Clin Psychopharmacol. 2010;30:235-44.

12 Hough D, Gopal S, Vijapurkar U, Lim P, Morozova M, Eerdekens M. Paliperidone palmitate maintenance treatment in delaying the timeto-relapse in patients with schizophrenia: a randomized, double-blind, placebo-controlled study. Schizophr Res. 2010;116:107-17.

13 Coppola D, Liu Y, Gopal S, Remmerie B, Samtani MN, Hough DW, et al. A one-year prospective study of the safety, tolerability and pharmacokinetics of the highest available dose of paliperidone palmitate in patients with schizophrenia. BMC Psychiatry. 2012;12:26.

14 Fleischhacker WW, Gopal S, Lane R, Gassmann-Mayer C, Lim P, Hough D, et al. A randomized trial of paliperidone palmitate and risperidone long-acting injectable in schizophrenia. Int $\mathrm{J}$ Neuropsychopharmacol. 2012;15:107-18.

15 Gopal S, Vijapurkar U, Lim P, Morozova M, Eerdekens M, Hough D. A 52-week open-label study of the safety and tolerability of paliperidone palmitate in patients with schizophrenia. J Psychopharmacol. 2011;25:685-97.

16 Marcus SC, Zummo J, Pettit AR, Stoddard J, Doshi JA. Antipsychotic adherence and rehospitalization in schizophrenia patients receiving oral versus long-acting injectable antipsychotics following hospital discharge. J Manag Care Spec Pharm. 2015;21:754-68.

17 Park EJ, Amatya S, Kim MS, Park JH, Seol E, Lee H, et al. Longacting injectable formulations of antipsychotic drugs for the treatment of schizophrenia. Arch Pharm Res. 2013;36:651-9.

18 Savitz AJ, Xu H, Gopal S, Nuamah I, Ravenstijn P, Janik A, et al. Efficacy and safety of paliperidone palmitate 3-month formulation for patients with schizophrenia: a randomized, multicenter, double-blind, noninferiority study. Int J Neuropsychopharmacol. 2016;19(7). pii: pyw018. doi:10.1093/ijnp/pyw018. Print 2016 Jul.

19 Berwaerts J, Liu Y, Gopal S, Nuamah I, Xu H, Savitz A, et al. Efficacy and safety of the 3-month formulation of paliperidone palmitate vs placebo for relapse prevention of schizophrenia: a randomized clinical trial. JAMA Psychiatry. 2015;72:830-9.

20 Marschner IC. Regional differences in multinational clinical trials: anticipating chance variation. Clin Trials. 2010;7:147-56.

21 Savitz AJ, Xu H, Gopal S, Nuamah I, Ravenstijn P, Hough D, et al. Efficacy and safety of paliperidone palmitate three-monthly formulation in East Asian patients with schizophrenia: subgroup analysis of a global, randomized, double-blind, Phase III, noninferiority study. Neuropsychiatr Dis Treat. 2017;13:2193-207.

22 Ramirez LF. Ethnicity and psychopharmacology in latin America. Mt Sinai J Med. 1996;63:330-1.

23 Csernansky JG, Mahmoud R, Brenner R; Risperidone-USA-79 Study Group. A comparison of risperidone and haloperidol for the prevention of relapse in patients with schizophrenia. N Engl J Med. 2002;346:16-22.

24 van Wijngaarden $B$, Schene $A H$, Koeter $M$, Vazquez-Barquero JL, Knudsen HC, Lasalvia A, et al. Caregiving in schizophrenia: development, internal consistency and reliability of the Involvement Evaluation Questionnaire--European Version. EPSILON study 4. European psychiatric services: inputs linked to outcome domains and needs. $\mathrm{Br} \mathrm{J}$ Psychiatry Suppl. 2000;(39):s21-7.

25 Caqueo-Urizar A, Urzua A, Fond G, Boyer L. Medication nonadherence among South American patients with schizophrenia. Patient Prefer Adherence. 2017;11:1737-44.

26 Brasso C, Bellino S, Bozzatello P, Montemagni C, Rocca P. Role of 3-monthly long-acting injectable paliperidone in the maintenance of schizophrenia. Neuropsychiatr Dis Treat. 2017;13:2767-79.

27 Savitz AJ, Xu H, Gopal S, Nuamah I, Hough D, Mathews M. Paliperidone palmitate 3-month treatment results in symptomatic remission in patients with schizophrenia: a randomized, multicenter, double-blind, and noninferiority study. Int Clin Psychopharmacol. 2017;32:329-36

28 Weiden PJ, Kim E, Bermak J, Turkoz I, Gopal S, Berwaerts J. Does half-life matter after antipsychotic discontinuation? A relapse comparison in schizophrenia with 3 different formulations of paliperidone. J Clin Psychiatry. 2017;78:e813-20.

29 Nicholl D, Nasrallah H, Nuamah I, Akhras K, Gagnon DD, Gopal S. Personal and social functioning in schizophrenia: defining a clinically meaningful measure of maintenance in relapse prevention. Curr Med Res Opin. 2010;26:1471-84.

30 Gopal S, Xu H, McQuarrie K, Savitz A, Nuamah I, Woodruff K, et al. Caregiver burden in schizophrenia following paliperidone palmitate long acting injectables treatment: pooled analysis of two double-blind randomized phase three studies. NPJ Schizophr. 2017;3:23.

31 Chien WT, Leung SF, Yeung FK, Wong WK. Current approaches to treatments for schizophrenia spectrum disorders, part II: psychosocial interventions and patient-focused perspectives in psychiatric care. Neuropsychiatr Dis Treat. 2013;9:1463-81.

32 Magana SM, Ramirez Garcia JI, Hernandez MG, Cortez R. Psychological distress among latino family caregivers of adults with schizophrenia: the roles of burden and stigma. Psychiatr Serv. 2007;58:378-84.

33 Carpiniello B, Pinna F. Critical appraisal of 3-monthly paliperidone depot injections in the treatment of schizophrenia. Drug Des Devel Ther. 2016;10:1731-42.

34 Ravenstijn P, Remmerie B, Savitz A, Samtani MN, Nuamah I, Chang $\mathrm{CT}$, et al. Pharmacokinetics, safety, and tolerability of paliperidone palmitate 3-month formulation in patients with schizophrenia: a phase-1, single-dose, randomized, open-label study. J Clin Pharmacol. 2016;56:330-9.

35 Jimenez-Castro L, Raventos-Vorst H, Escamilla M. Substance use disorder and schizophrenia: prevalence and sociodemographic characteristics in the Latin American population. Actas Esp Psiquiatr. 2011; 39:123-30. 